\title{
Improving information given to patients before endoscopy: a regional audit
}

\author{
A R Tanner, C W Wilson
}

\begin{abstract}
To improve the information given to patients before endoscopy an audit was performed in 16 of 18 endoscopy units in Northern region. Details of current endoscopy information leaflets provided by the 16 respondents were discussed by nurses and consultants from the participating units, and a standard, including 12 separate items, was agreed. Each unit was provided with a comparison of its current leaflet with the standard, which highlighted areas for potential improvement. Six months later the participating units were again asked to provide details of the information; 13 replied, 11 of which had produced new leaflets and two which were in the process of doing so. In the initial survey only $35 \%$ (range $8-67 \%$ ) of the items in the standard were included in the leaflets. Particular omissions were an indication of risks of procedures (three units), notification of follow up procedures (two), details for obtaining the results of the endoscopy (five), advice for people with diabetes (two) and providing a contact number for the endoscopy unit (four). In the repeat audit all 11 units had made changes to their leaflets and, overall, $80 \%$ of the items were included. Through this simple audit the range of information given to patients attending for endoscopy in the region has improved.

(Quality in Health Care 1994;2:34-36)
\end{abstract}

\section{Introduction}

The patient's charter states that all patients "have the right to be given a clear explanation of any treatment or investigation proposed including any risks ...." Oral communication is central to clinical care, although in many circumstances this form of communication alone is not enough. Spoken messages may be poorly remembered, and they can be inconsistent, incomplete, or inaccurate; facts may be omitted, diluted, embellished, or condensed. Information sheets are an important adjunct to oral communication, providing a consistent and comprehensive message, although care must be taken with both format and language. ${ }^{2}$ It is important that written information is of such a standard that it is likely to fulfil its purpose.
Most endoscopy units provide information leaflets for patients that describe the procedure and outline other pertinent information, but the content of these leaflets is not guided by explicit standards. This study set out to assess the range of information described in the leaflets issued by endoscopy units in the Northern region and then to use that information as the basis of discussion to agree a standard among gastroenterologists in the region aimed at improving information.

\section{Methods}

All 18 endoscopy units in the Northern region were invited to take part in the audit and to send a copy of their endoscopy information sheets to ART; 16 units responded. The various items included in the sheets were categorised by CWW.

A series of meetings was held to discuss the content of the leaflets, including meetings at individual units, coordinated by CWW; a meeting of the regional endoscopy nurses' meeting (attended by CWW); and a regional meeting of consultant gastroenterologists and staff of endoscopy units (attended by CWW and ART). A standard consisting of 12 items was approved. Ownership of the standard was encouraged through these discussions but a formal "signing up" was not thought to be appropriate.

After the initial data had been collected each unit was contacted by the lead clinician in audit (ART) and sent a comparison of the information contained in its leaflet with that of the agreed standard with suggestions for improvements. The information was sent to the senior endoscopy nurse and the consultant in charge of the endoscopy unit, and each unit was provided with an analysis of only its own leaflets and had no knowledge of the performance of other units. Six months later the endoscopy units were again asked to send in their information leaflets, and the information was again compared with the agreed standard.

\section{Results}

Sixteen of the 18 endoscopy units responded to the initial request for details of written information given to patients; one unit indicated that patients were not provided with written information before endoscopy. 
1 Information should be clear, informal, and understandable to the lay person, avoiding the use of jargon

2 There should be clear directions for finding the endoscopy unit

3 There should be a contact number for the endoscopy unit

4 There should be accurate and unambiguous statements regarding fasting or bowel preparation

5 Sedation and procedural risks should be stated

6 Consent procedures should be stated

7 Care after the procedure, including side effects, should be described

8 "Do's and Dont's" on going home should be stated

9 Information on getting the result of the endoscopy should be included

10 Follow up arrangements should be stated where applicable

11 A statement asking for valuables to be left at home should be included

12 Instructions for diabetic patients should be included, perhaps just a simple instruction suggesting they contact the unit

Agreed standard for information leaflets given or sent to prospective patients attending for endoscopy

CONSTRUCTING THE STANDARD

The analysis of the information leaflets showed a wide range of issues relevant to people experiencing endoscopy. Through the

Comparison of content of leaflet submitted during first and second audit cycles against standards

\begin{tabular}{|c|c|c|c|c|c|c|c|c|c|c|c|c|c|}
\hline \multirow[b]{2}{*}{ Unit } & \multirow[b]{2}{*}{$\begin{array}{l}\text { Audit } \\
\text { cycle }\end{array}$} & \multirow[b]{2}{*}{1} & \multirow[b]{2}{*}{2} & \multirow[b]{2}{*}{3} & \multirow[b]{2}{*}{4} & \multirow[b]{2}{*}{5} & \multicolumn{2}{|c|}{ Standard } & \multirow[b]{2}{*}{8} & \multirow[b]{2}{*}{9} & \multirow[b]{2}{*}{10} & \multirow[b]{2}{*}{11} & \multirow[b]{2}{*}{12} \\
\hline & & & & & & & 6 & 7 & & & & & \\
\hline A & $\begin{array}{l}1 \\
2\end{array}$ & + & - & + & + & $\bar{t}$ & - & $\overline{+}$ & $\overline{+}$ & - & $\overline{+}$ & + & + \\
\hline B & $\begin{array}{l}1 \\
2\end{array}$ & & $\begin{array}{l}+ \\
\text { ply }\end{array}$ & + & + & + & + & + & - & - & - & - & - \\
\hline C & $\begin{array}{l}1 \\
2\end{array}$ & $\begin{array}{l}+ \\
+\end{array}$ & $\begin{array}{l}+ \\
+\end{array}$ & $\begin{array}{l}+ \\
+\end{array}$ & + & $\begin{array}{l}- \\
-\end{array}$ & - & $\begin{array}{l}- \\
-\end{array}$ & $\begin{array}{l}+ \\
+\end{array}$ & + & - & - & + \\
\hline D & $\begin{array}{l}1 \\
2\end{array}$ & + & - & $\begin{array}{l}+ \\
+\end{array}$ & + & + & $\begin{array}{l}+ \\
+\end{array}$ & + & $\begin{array}{l}+ \\
+\end{array}$ & $\begin{array}{l}+ \\
+\end{array}$ & $\begin{array}{l}- \\
-\end{array}$ & - & - \\
\hline $\mathrm{E}$ & $\begin{array}{l}1 \\
2\end{array}$ & & $\stackrel{+}{e a f l}$ & beir & + & $\bar{d}$ & - & + & + & - & - & + & - \\
\hline $\mathrm{F}$ & $\begin{array}{l}1 \\
2\end{array}$ & $\begin{array}{l}- \\
-\end{array}$ & - & $\overline{+}$ & + & - & $\overline{+}$ & $\overline{+}$ & $\begin{array}{l}- \\
-\end{array}$ & $\begin{array}{l}- \\
-\end{array}$ & - & $\begin{array}{l}- \\
-\end{array}$ & $\begin{array}{l}- \\
-\end{array}$ \\
\hline G & $\begin{array}{l}1 \\
2\end{array}$ & $\overline{+}$ & + & - & $\begin{array}{l}+ \\
+\end{array}$ & $\begin{array}{l}- \\
-\end{array}$ & - & + & $\overline{+}$ & + & - & - & - \\
\hline $\mathrm{H}$ & $\begin{array}{l}1 \\
2\end{array}$ & & . & $\begin{array}{l}\text { not } \\
\text { beir }\end{array}$ & it & & & & & & & & \\
\hline I & $\begin{array}{l}1 \\
2\end{array}$ & & $\begin{array}{c}+ \\
\text { ply }\end{array}$ & + & + & - & - & + & + & - & - & + & - \\
\hline J & $\begin{array}{l}1 \\
2\end{array}$ & - & $\overline{+}$ & - & + & $\overline{+}$ & - & - & $\overline{+}$ & $\overline{+}$ & + & - & $\overline{+}$ \\
\hline K & $\begin{array}{l}1 \\
2\end{array}$ & + & + & $\overline{+}$ & $\overline{+}$ & $\overline{+}$ & $\overline{+}$ & $\begin{array}{l}+ \\
+\end{array}$ & $\begin{array}{l}+ \\
+\end{array}$ & + & + & $\begin{array}{l}- \\
-\end{array}$ & $\overline{+}$ \\
\hline L & $\begin{array}{l}1 \\
2\end{array}$ & & $\begin{array}{c}+ \\
\text { ply }\end{array}$ & - & + & - & - & - & - & + & - & - & - \\
\hline$M$ & $\begin{array}{l}1 \\
2\end{array}$ & $\overline{+}$ & + & $\overline{+}$ & + & $\overline{+}$ & $\overline{+}$ & + & - & + & - & + & + \\
\hline $\mathbf{N}$ & $\begin{array}{l}1 \\
2\end{array}$ & & ply & - & + & - & - & - & - & - & - & - & - \\
\hline O & $\begin{array}{l}1 \\
2\end{array}$ & + & + & $\overline{+}$ & + & - & - & + & + & $\bar{t}$ & $\overline{+}$ & + & + \\
\hline $\mathbf{P}$ & $\begin{array}{l}1 \\
2\end{array}$ & & spo & & & & & & & & & & \\
\hline Q & $\begin{array}{l}1 \\
2\end{array}$ & $\overline{+}$ & + & $\overline{+}$ & + & + & - & - & + & $\overline{+}$ & - & - & - \\
\hline $\mathbf{R}$ & $\begin{array}{l}1 \\
2\end{array}$ & + & $\overline{+}$ & $\overline{+}$ & + & $\begin{array}{l}+ \\
+\end{array}$ & + & + & + & + & + & $\overline{+}$ & $\overline{+}$ \\
\hline
\end{tabular}

$+=$ Presence of item; $-=$ absence of item. discussions 12 items were agreed as being important and were included in the standard (box). The emphasis is on the importance of individual items by different units varied, and some units were not prepared to incorporate all of the items.

CONTENT OF LEAFLETS

The number of "standard" items included in the leaflets originally received ranged from three to eight items (table). Unit J did not send information initially. During the second cycle more items from the standard were included, ranging from six to 12 items. Units $\mathrm{C}$ and $\mathrm{D}$ did not change their information leaflets. Only one unit $(P)$ never provided any information, four did not reply to the second request, and information is not yet available from two units that are preparing new leaflets.

CHANGES IN CONTENT OF LEAFLETS

A total of 67 out of a possible $192(35 \%)$ items were included in information leaflets provided by the 15 units that reponded to the initial request. After the leaflets had been updated instructions about fasting or bowel preparation were most commonly included, followed by information on care after the procedure and directions to the unit and description of endoscopy and what to do on returning home. Before the standard setting exercise only three units provided written information on sedation and risks of the procedure and two on follow up arrangements; four provided a contact number and five information about obtaining the results of the endoscopy. In the second cycle these figures had improved to eight, six, 11, and 10 units respectively.

For those 13 units responding to the second request 106 out of a possible $132(80 \%)$ items of information were now included in their information leaflets. Items concerning risks, consent, follow up arrangements, valuables, and information for people with diabetes were those that remained least likely to be included.

\section{Discussion}

Providing patients with full, consistent, and unambiguous information is an important aspect of the quality of care. Written information is a crucial adjunct to full oral explanation by clinicians, especially in areas such as open access endoscopy, ${ }^{3}$ in which the referring clinician may only have a limited knowledge of the particular procedures. This study showed that many existing leaflets describing the process of endoscopy are inadequate but were improved through the process of regional audit.

There is a place for both information leaflets and sympathetic explanation by the clinician. This study showed that a standard can be agreed regionally and that audit can promote effective change with improved communication to patients. The standard agreed is not necessarily rigid, and individual units can use it as a framework for their own 
circumstances. Subsequent assessment confirmed that most units accepted the majority of the items in the standard and incorporated them into their new leaflets. A similar process could be used in other areas of clinical practice.
1 Department of Health. The patients' charter: London: HMSO, 1991.

2 Cox GB. The art of writing patient education materials. American Medical W'Thers" Association Foumal $9 ; 4: 11-4$

3 Bramble MG Cooke WM Corbet WA. Cann PA. Clark D), Contractor B, it al. Organising unrestricted open access gastroscopy in South Tees. (Fm 1993;34:422-7. 